\title{
СОЦИАЛЬНО-ПОЛИТИЧЕСКОЕ СОДЕРЖАНИЕ ПОНЯТИЯ ‘ОТІUМ' В СОЧИНЕНИЯХ ЦИЦЕРОНА
}

\author{
А. М. Брагова \\ Нижегородский государственный лингвистический университет им. Н.А. Добролюбова \\ Россия, 603155 г. Нижний Новгород, ул. Минина, 31а \\ Брагова Арина Михайловна - arbra@mail.ru
}

Статья посвящена анализу социально-политического понятия отіит в оценке Цицерона на основе контекстной семантики. Понятие otium используется Цицероном, с одной стороны, в политическом смысле - как мир, спокойствие внутри / вне Рима или как уход от государственных дел (вынужденный или добровольный). С другой стороны, отіит является социальной категорией и подразумевает досуг, свободное время. В последнем значении цицероновское понятие otium означает либо время для пассивных познавательных занятий (например, для изучения греческого философского наследия), либо время для активных познавательных занятий (например, для писательской деятельности).

Ключевые слова: Цичерон, Древний Рим, отіит, мир, досуг, социальный, политический.

\section{THE SOCIALAND POLITICAL MEANING OF THE CONCEPT OTIUM IN CICERO’S WRITINGS}

\author{
A. M. Bragova \\ Linguistics University of Nizhny Novgorod \\ 31a Minin St., 603155 Nizhny Novgorod, Russia \\ $凶$ Bragova Arina - arbra@mail.ru
}

The article is devoted to the analysis of the social and political concept otium in Cicero's assessment based on the contextual semantics. The concept otium is used by Cicero, on the one hand, in a political sense - as peace, tranquillity in / outside Rome or as retirement from public affairs (forced or voluntary). On the other hand, otium is a social category and means leisure, free time. In this meaning Cicero's concept otium means either time for passive cognitive exercises (for example, for studying the Greek philosophical heritage) or time for active cognitive exercises (for example, for writing books).

Keywords: Cicero, Ancient Rome, otium, peace, leisure, social, political.

Сочинения Цицерона содержат определенный понятийный аппарат, который состоит как из исконно римских понятий (auctoritas, dignitas, otium, mores majorum, optimates и др.), так и из древнегреческих, например, взятых из учения стоиков о практической этике (vir bonus, prudentia, justitia, beneficentia, magnitudo animi, temperantia и др.). В статье речь пойдет о римском понятии otium и анализе его употребления Цицероном.

Научная литература о понятии otium у древнеримских авторов, в частности, у Цицерона, довольно обширна [1, с. $160-161 ; 2$, с. $41-68 ; 3$, с. $20,83-87,103,146-147$; 4, c. $106-$ $107 ; 5$, c. $56-59 ; 6$, c. $113-127 ; 7$, c. $144-155 ; 8$, c. $43-50 ; 9$, c. 12 , $291 ; 10$, c. $3-26 ; 11$, c. $92-93$; 12, c. $5-16 ; 13$, c. $193-199 ; 14$, c. $77-78 ; 15$, c. $370 ; 16$, c. $125 ; 17$, c. $35-36 ; 18$, c. $32 ; 19$, c. $34-$ $42,48-49,52,61-62 ; 20$, с. $68 ; 21$, с. $70-71 ; 22$, с. $57-58 ; 23$, с. 33-34; 24, с. 18]. Это связано, по-видимому, с многообразием точек зрения по данному вопросу в исследовательской литературе. Мы полагаем, что понятие otium является одним из базовых понятий для римского общества позднереспубликанского периода, важно для понимания процессов, проходивших в нем, и именно поэтому привлекает внимание исследователей.

Понятие otium встречается в сочинениях Цицерона неоднократно, причем как в политическом (причем Цицерон был первым, кто использовал otium в политическим контексте [13, с. 194; 3, с. 84]) (например, Cic. ad Att. 1.14.4, 1.17.5-6, 1.20.5, 2.1.4, 2.1.11, 2.14.1, 4.6.2, 5.14.1, 6.1.11, 7.7.5, 7.18.2, 9.7.1, 9.11.2, 9.11a.1, 14.2.3, 14.21.26 14.21.4, 14.22.1, 15.1.4, 15.2.3, 16.16b.2, 16.16c.3; ad Brut. 1.2a.1,
1.15.4; ad fam. 1.8.4, 1.9.10, 1.9.21, 2.13.3, 2.16.2, 2.17.5, 2.18.3, 3.7.1, 4.4.4, 4.9.3, 5.7.1, 5.21.2, 9.9.1, 10.32.5, 11.2.2, 11.20.4, 11.28.8, 12.1.1, 12.17.1; ad Q. fr. 1.1.25, 1.1.34, 2.13.5, 3.5.5; de off. 1.77, 2.41; de orat. 1.1, 1.2, 1.32, 2.143, 2.144, 3.122, 3.131; de rep. 1.6, 1.63, 2.26, 2.43; de nat. deor. 1.7; de prov. cons. 24, 39; in Pis. 4, 30; pro Sest. 5, 15, 46, 74, 98-100, 104, 110, 138, 139; pro Sul. 26 и др. соч.), так и в общественно-философском, социальном значении (например, Cic. ad Att. 1.5.4, 1.6.1, 1.7, 1.19.1, 2.3.4, 2.4.2, 2.6.1, 2.14.2, 4.16.2, 5.20.9, 12.40.2, 14.8.2; ad Q. fr. 2.2.1, 2.12.2, 2.15.1, 3.9.2; ad fam. 2.9.3, 3.11.4, 6.18.5, 7.1.1, 7.33.2, 8.1.1, 10.28.3, 10.31.6, 11.29.3, 12.30.1, 15.4.16; de leg. 1.9, 3.14; de off. 1.69, 1.153, 1.156, 2.4, 3.1-3; de rep. 1.1, 1.7-9, 1.14, 3.4; orat. 108; de orat. $1.3,1.14,1.22,1.57,1.79,1.95,1.164,1.224,1.255,2.19-20$, 2.22, 2.57, 2.59, 2.139, 3.56-58, 3.211; pro Balb. 15; pro Cael. 1; pro Planc. 66; pro Sest. 57; pro Arch. 3, 12; pro Flac. 75). Сочинения, как мы видим, имеют разную направленность (речи, философские и политические трактаты, письма), что позволяет сделать вывод о том, что Цицерон использовал данное понятие систематически.

В политическом контексте otium, во-первых, подразумевает мир в Римской республике (Сic. ad Att. 1.14.4, 6.1.11, 7.7.5, 9.7.1, 14.21.2, 14.21.4, 14.22.1, 15.1.5, 15.2.3; ad fam. 12.1.1, 12.17.1; ad Q. fr. 2.13.5; de off. 1.77, 2.41). Например, в письме Аттику Цицерон пишет, что он не удивляется, что Аттик возлагает на Помпея всякую надежду на мир (spem omnem oti) (Cic. ad Att. 6.1.11). В этом отрывке речь явно идет об otium как антониме гражданской войны [19, с. 49]. Вовторых, otium употребляется Цицероном для обозначения 
мира, спокойствия, отсутствия военных действий за пределами Римской республики: в Галлии (Cic. ad Att. 1.20.5, 2.1.4, 2.1.11), на границе с парфянами (Cic. ad Att. 5.14.1), в Сирии (Cic. ad fam. 2.17.5), в Азии (Cic. ad Q. fr. 1.1.34). Так, например, в письме Аттику Цицерон порицает Метелла за то, что тот не очень радовался сообщению о спокойствии в Галлии (otium nuntiari e Gallia non magno opere gaudet) (Cic. ad Att. 1.20.5). В значении «мир», «спокойствие» otium часто сочетается со словами tranquillitas (Cic. in Pis. 4: tranquillitatis atque otii; pro Sest. 110: otio et tranquillitate rei publicae), pax (Cic. ad Q. fr. 3.5.5: ad otium pacemque converto; de prov. cons. 39: diligentissimo custode pacis atque otii; de rep. 1.63: in pace et otio, 2.26: otii et pacis; in Pis. 30 : bellum ac tumultum paci atque otio concessurum), dignitas (Cic. pro Sest. 98: id quod est praestantissimum maximeque optabile omnibus sanis et bonis et beatis, cum dignitate otium; de orat. 1.1: ut vel in negotio sine periculo vel in otio cum dignitate esse possent; ad fam. 1.9.21: omnibus nobis in administranda re publica propositum esse debeat id ... cum dignitate otium), что подтверждает мысль о том, что otium для Цицерона означает справедливый мир, отсутствие войны. В-третьих, Цицерон использует otium как политическое понятие в значении ухода, отстранения от государственных дел, которое может случаться как добровольно, т. е. по воле самого политика, например, в связи с отставкой по старости (Cic. ad Att. 4.6.2; ad fam. 1.17.5, 2.16.2, 4.4.4; de orat. 1.32), так и вынужденно, в связи с отстранением политика от власти, уходом в отставку под давлением, в связи с изгнанием (Сic. ad Att. 2.14.1; ad fam. 9.9.1; de orat. 2.143-144, de nat. deor. 1.7) [2, с. 45]. Например, Цицерон задается вопросом о том, что, если бы захотелось прекратить (заниматься государственными делами) и убежать в гавань спокойствия? (quid si cessare libeat et in oti portum confugere?) (Cic. ad Att. 4.6.2). О вынужденном отдыхе Цицерон пишет, что мы устали от бездействия (otio langueremus), когда она (республика) вынужденно была управляема советом и заботой одного человека (еат unius consilio atque cura gubernari necesse esset) (Cic. de nat. deor. 1.7). Otium в значении ухода от государственных дел иногда сочетается с прилагательным honestus (Cic. ad Att. 1.17.5: me ambitio quaedam ad honorum studium, te autem alia minime reprehendenda ratio ad honestum otium duxit; ad fam. 4.4.4: meque metuo ne etiam in ceteris rebus honesto otio privarim, 4.9.3: honesto otio tenueris et statum et famam dignitatis tuae, 5.21.2: nullius vim plus valere volui quam honestum otium; pro Sul. 26: nullum aliud mihi praemium ab senatu populoque Romano nisi honestum otium postularem), что приводит к мысли о том, что в данном случае под понятием otium подразумевается заслуженный или «незаслуженный» уход, отдых от государственных дел. В связи с этим интересно замечание Страупа о том, что римлянин, чей otium обозначен как honestum, много лет хорошо служил на пользу государства. Otium того, кто служил плохо, можно назвать inhonestum $[19$, с. 48]. Об этом же пишет и МасКоннелл [23, с. 33].

Цицероновское понятие otium также имеет определенный общественно-философский [7, с. 144-155; 10, с. 3-26; 12 , с. $5-16 ; 24$, с. 18] и социальный смысл. Как замечает Страуп, во времена поздней Республики otium обыкновенно являлся частью некоего «социального кода» [19, с. 35]. В общественно-философском и социальном смысле otium подразумевает время досуга, свободное время. Это может быть время, потраченное на изучение чего-либо (в случае с Цицероном и римлянами высшей страты общества, это, на- пример, изучение греческого философского наследия) (Сіс. ad fam. 7.1.1, 15.4.16; de orat. 2.59; pro Planc. 66; pro Flac. 75), либо время для активных познавательных занятий (например, для писательской деятельности) (Сic. ad Att. 12.40.2; ad fam. 8.1.1; pro Arch. 3, 12). Как справедливо замечает Страуп, otium и подобные термины используются для обозначения времени для работы с текстом (textual time), когда имеют место интеллектуальная беседа (intellectual discussion) $и$ написание текста (textual production): otium в таком случае обозначает не простое безделье (simple inactivity), а особый вид работы с текстом (rather a very specific sort of textual engagement) [19, с. 34]. Об этом можно прочесть у цицерона в трактате "Об ораторе», где от имени Марка Антония он пишет о том, что тот имеет обыкновение читать для удовольствия, когда есть свободное время (delectationis causa, cum est otium, legere soleo) (Cic. de orat. 2.59). О писательстве Цицерон замечает, что требуется много свободного времени не только записать об этом (о событиях, происходящих в Риме), но вообще за этим понаблюдать» (cujus otii esset non modo perscribere haec, sed omnino animadvertere) (Cic. ad fam. 8.1.1). Интересно, что в значении «досуг» понятие otium часто сочетается с такими словами, как studium (Cic. de orat. 1.22; otio studioque abundantis partitionem jam quandam artium fecisse video; pro Arch. 3: otium ac studium minime in judiciis periculisque tractata est), requies (Cic. de orat. 1.224: philosophorum autem libros reservet sibi ad hujusce modi Tusculani requiem atque otium), philosophia (Cic. ad fam. 15.4.16: societas studiorum atque artium nostrarum, quibus a pueritia dediti ac devincti soli propemodum nos philosophiam veram illam et antiquam, quae quibusdam otii esse ac desidiae videtur). Кроме того, otium в значении «свободное время» в каких-то пассажах сочетается с понятием negotium "дело», "занятие», "работа» (Сic. de off. 1.156: Nec enim locus ullus est praetermissus ab iis, qui ad leges, qui ad mores, qui ad disciplinam rei publicae pertineret, ut otium suum ad nostrum negotium contulisse videantur), а в какихто - противопоставляется (Сic. de orat. 1.1: ut vel in negotio sine periculo vel in otio cum dignitate esse possent), и такая антитеза otium - negotium подтверждает идею о понимании otium как свободного времени.

Таким образом, цицероновское понятие otium довольно многозначно. Как политическая категория, оно означает мир и спокойствие как внутри, так и за пределами Рима, а также заслуженный отдых после многолетнего служения государству. Как социальная категория, otium подразумевает досуг, свободное время, которое можно использовать для чтения или писательской деятельности.

\section{ЛИТЕРАТУРА}

1. Утченко С.Л. Кризис и падение римской республики. Москва: Наука, 1965.

2. Межерицкий Я.Ю. Iners otium // Быт и история в античности. Москва: Наука, 1988. С. 41-68.

3. Брагова А.М. Марк Туллий Цицерон об идеальном гражданине и государстве. Дис. ... канд. ист. наук. Нижний Новгород, 2005.

4. Демина С.С. Гражданское сознание и поведение римлян в І в. до н.э. Владимир: Изд-во ВлГУ, 2012.

5. Доманина С.А. Многозначность понятия otium в трудах римских авторов эпохи поздней республики // Вестник Нижегородского университета им. Н. И. Лобачевского. 2012. №1(2). С. 56-59.

6. Rèmy E. Dignitas cum otio // Le Musèe Belge. 1928. No. 32. Pp. 113127. 
7. Lepore E. Il princeps ciceroniano e gli ideali politici della tarda repubblica. Napoli, 1954.

8. Balsdon J. Auctoritas, Dignitas, Otium // The Classical Quarterly. 1960. Vol. 10. Pp. 43-50.

9. Petersson T. Cicero: a Biography. New York: Cooper Square, 1963.

10. Boyancè P. Cicéron et la vie contemplative // Latomus. 1967. No. 2. Pp. 3-26.

11. Wirszubski Ch. Libertas as a Political Idea at Rome during the Late Republic and Early Principate. Cambridge: Cambridge University Press, 1968.

12. Perlich D. Otium oder accedere ad rem publicam: Das Problem der politischen Betätigung bei Cicero // Der altsprachliche Unterricht. 1970. Bd. 13 (1). Pp. 5-16.

13. Wood N. Cicero's Social and Political Thought. Berkeley: University of California Press, 1988.

14. Colish M.L. The Stoic Tradition from Antiquity to the Early Middle Ages. Leiden, New York; Kobenhavn, Köln: E.J. Brill, 1990.

15. De Ste. Croix G. E. M. The Class Struggle in the Ancient Greek World from the Archaic Age to the Arab Conquests. Ithaca, New York: Cornell University Press, 1998.
16. Thompson N. ed. Instilling Ethics. Lanham, Boulder, New York, Oxford: Bowman and Littlefield Publishers, Inc., 2000.

17. Radford R.T. Cicero: A Study in the Origins of Republican Philosophy. Amsterdam, New York, 2002.

18. Kaster R.A., tr. Cicero: Speech on Behalf of Publius Sestius. Oxford: Clarendon Press, 2006.

19. Stroup S.C. Catullus, Cicero and a Society of Patrons: The Generation of the Text. Cambridge: Cambridge University Press, 2010.

20. Leonhardt J. Latin: Story of a World Language / transl. by K. Kronenberg. Cambridge, London: The Belknap Press of Harvard University Press, 2013.

21. Jenkyns R. God, Space and City in the Roman Imagination. Oxford: Oxford University Press, 2013.

22. Zarecki J. Cicero's Ideal Statesman in Theory and Practice. New York: Bloomsbury, 2014.

23. McConnell S. Philosophical Life in Cicero's Letters. Cambridge: Cambridge University Press, 2014.

24. Altman W. H. F. The Revival of Platonism in Cicero's Late Philosophy: Platonis aemulus and the Invention of Cicero. Lantham: Lexington Books, 2016. 